Prosiding Seminar Nasional Teknologi Informasi dan Kedirgantaraan : Peran Teknologi untuk Revitalisasi Bandara dan Transportasi Udara, Yogyakarta, 10 Desember 2019

SENATIK 2019, Vol. V, ISBN 978-602-52742-1-3

DOI: $10.28989 /$ senatik.v5i0.319

\title{
ANALYSIS TURN AROUND TIME C03-CHECK PACKAGE ON AIRBUS A320-200
}

\author{
Fajar Khanif Rahmawati ${ }^{1)}$, Suyudi Imam Prakoso ${ }^{2)}$ \\ Program Studi Teknik Dirgantara \\ Sekolah Tinggi Teknologi Adisutjipto \\ J1.Janti Blok.R, Lanud Adisutjipto Yogyakarta \\ Email: ${ }^{1}$ fajar.khanif@ gmail.com
}

\begin{abstract}
Aircraft maintenance is one of the consequences due to aircraft utilization. C03-check package on an Airbus A320-200 aircraft is one of the scheduled maintenance with interval every 22,500 flight hours, or 15000 flight cycles, or 72 months whicever comes firts. As one of scheduled maintenance, the planning of maintenance activities must be planned as well as possible to make activities carried out efficiently and effectively in terms of time and resources. Preliminary data to make the planning is sourced from the MPD (maintenance planning document).The data included of the scope of work, manhours, and man power. The data obtained is processed using the CPM (Critical Path Method). The results of data processing, it is obtained that the C03-check package on the Airbus A320-200 aircraft takes 4 (four) days, with the critical path on the AD-D1-D2-D3-D4-D4-D5-D6-D7-G aircraft, in the area empenage access panel with the number of hours needed is 41.3 hours.
\end{abstract}

Keywords: Maintenance, Planning, Manpower, Manhours.

\section{Pendahuluan}

Untuk mewujudkan keamanan, keselamatan maupun kelaikan dari penggunaan pesawat udara tersebut maka perlu dilakukannya perawatan yang teratur agar pesawat dapat laik terbang (airworthiness). Perawatan untuk pesawat udara dibagi menjadi 2 (dua) yaitu preventive dan corrective. Perawatan preventive adalah perawatan yang bertujuan untuk mencegah kerusakan dari komponen pada pesawat udara, sedangkan corrective bertujuan untuk memperbaiki pesawat udara setelah terjadi kerusakan[2].

Salah satu perawatan yang termasuk dalam perawatan preventive adalah $C$-check. Perawatan pesawat ini termasuk dalam perawatan hard time yaitu perawatan yang sudah ditentukan waktunya oleh manufaktur pesawat. $C$-check dilakukan pada setiap 24 bulan atau 7.500 flight hours atau 5000 flight cycle untuk pesawat Airbus A320-200[1]. Sebelum melakukan kegiatan perawatan, dilakukan perencanaan dengan baik oleh pihak product planning and control maupun dari pihak engineering.

C03-check adalah salah satu paket $C$-check yang ketiga yang merupakan major maintenance. Interval pelaksanaannya setiap 22.500 flight hours, atau 15000 flight cyclse, atau 72 months, tergantung waktu yang lebih dahulu tercapai. Pekerjaan tersebut meliputi Operational Check, Inspection, Repair, Cleaning, Lubrication, Remove and Install,[1]. Dalam perencanaan perawatan bagian produksi mendapatkan TAT (turn around time) dari engineering 
yang telah disepakati dengan pihak operator. Untuk mengetahui lebih pasti TAT (turn around time) yang dibutuhkan maka bagian produksi perlu melakukan perencanaan agar TAT (turn around time) yang ditentukan dapat berjalan dengan efektif dan efisien.

\section{Metode Penelitian}

Penelitian ini menggunakan metode kuantitatif. Metode kuantitatif yang digunakan dalam penelitian ini merupakan proses menemukan pengetahuan dengan data berupa angka sebagai alat untuk menganalisis keterangan mengenai apa yang ingin diketahui[3]. Data yang diperlukan dalam penelitian ini adalah data waktu pelaksanaan dari setiap pekerjaan yang dilakukan pada perawatan C03-check yang diperoleh dari data MPD (maintenance planning document) dari pesawat Airbus A320-300. Data tersebut sudah disusun dalam bentuk manhours untuk setiap pekerjaan pada perawatan CO3-check, selain itu data yang diperoleh adalah jumlah man power yang tersedia pada saat perawatan tersebut, serta jumlah man hours dalam sehari. Adapun data pekerjaan pada paket C03-check terdapat 350 item taskcard sebagaimana dalam tabel 1 .

Tabel 1. Data Pekerjaan C03-check

(Sumber: MPD Airbus A320-200)

\begin{tabular}{|l|l|c|}
\hline No. & \multicolumn{1}{|c|}{ Jenis Pekerjaan } & Jumlah Pekerjaan \\
\hline 1. & Cleaning & 4 \\
\hline 2. & Inspection & 150 \\
\hline 3. & Lubrication & 37 \\
\hline 4. & Operational Check & 23 \\
\hline 5. & Remove/Install & 10 \\
\hline 6. & Open/Close Panel & 11 \\
\hline 7. & Preparation + Post Maintenance & \\
\hline
\end{tabular}

\section{Hasil dan Pembahasan}

Perencanaan meliputi penetapan keputusan mengenai apa (what) yang diharapkan untuk dikerjakan, kapan (when) hal tersebut akan dikerjakan, siapa (who) yang akan melaksanakannya, dan bagaimana (how) sasaran tujuan akan dicapai[5]. Metode CPM (crictical path method) digunakan untuk menentukan TAT (turn around time) yang akan dilaksanakan untuk perawatan C03-check. CPM (Critical Path Method) merupakan metode analisis jalur yang menggunakan jaringan kerja. Pengolahannya dilakukan dengan menyusun jaringan kerja yang diidentifikasikan ke arah aktivitas - aktivitas dan menggunakan simple time estimates pada setiap aktivitas yang menunjukkan jangka waktu pelaksanaan[8]. Dari jaringan CPM (Critical Path Method) yang telah tersusun akan diketahui jalur kritis dari pekerjaan C03-check. Jalur kritis merupakan jalur yang menunjukan adanya pekerjaan dengan waktu yang paling lama, jika jalur kritis mengalami keterlambatan maka proyek yang dilakukan akan selesai tidak tepat waktu[4].

Melalui data yang telah diperoleh, untuk menentukan TAT (turn around time) adalah dengan menghitung waktu kerja efektif dalam sehari, Jam kerja efektif adalah jumlah jam kerja normal dikurangi dengan waktu kerja yang hilang karena tidak bekerja (allowance) seperti buang air, melepas lelah, istirahat makan,dan sebagainya [6]. 


$$
\begin{aligned}
& \text { Shift Pagi } \quad=07: 30-11: 30 \quad=4: 00 \text { jam bekerja } \\
& =13: 00-15: 00 \quad=2: 00 \text { jam bekerja } \\
& \text { Total shift pagi }=04: 00+2: 00 \quad=6: 00 \text { jam bekerja } \\
& \text { Shift Siang } \quad=14: 30-17: 30 \quad=3: 00 \text { jam bekerja } \\
& =19: 00-21: 30 \quad=2: 30 \text { jam bekerja } \\
& \text { Total shift siang } \quad=03: 00+2: 30 \quad=5: 30 \text { jam bekerja }
\end{aligned}
$$

Untuk memudahkan dalam perencanaan dan pelaksanaan kegiatan perawatan, maka paket pekerjaan dalam CO3-check dikelompokan menjadi kelompok pekerjaan berdasarkan zona access panel sebagai berikut :

1. Maintenance Preparation

2. Access Door Panel

3. Engine Access Panel

4. Empenage Access Panel

5. Fuselage Access Panel

6. Wing Access Panel

7. Post Maintenance

Dalam pembuatan rencana penjadwalan diperlukan diagram network untuk menentukan urutan keseluruhan kegiatan. Untuk menyusun diagram network perlu diketahui kegiatan apa yang menjadi predecessor, successor, dan concurrent[7]. Berikut urutan keseluruhan kegiatan setiap jalur pada C03-check:

1. Maintenance Preparation

2. Cleaning

3. Open Panel

4. Operational/Functional Check

5. General Visual Inspection

6. Detailed Visual Inspection

7. Special Detailed Visual Inspection

8. Remove/Install

9. Lubrication

10. Close Access Panel

11. Post Maintenance

Setelah dikelompokan kemudian setiap pekerjaan ditentukan jumlah manhours yang dibutuhkan untuk setiap pekerjaan tersebut dengan rumus (1).

$$
T A T=\frac{\text { Man Hours Manufacture }}{\text { Man Power Required }}[4]
$$

Setelah dikelompokan dan diketahui manhours dari setiap pekerjaan maka dilakukan perhitungan maju untuk menentukan waktu paling awal kegiatan dapat diselesaikan atau EF (early finish) dan perhitungan mundur untuk menentukan waktu paling lambat kegiatan boleh untuk dimulai atau 
LS (latest start) dari setiap pengelompokan pekerjaan yang akan dilakukan. Penentuan tersebut menggunakan rumus (2) dan (3) untuk perhitungan maju dan mundur :

waktu paling awal $(E F)=E S+D[4]$

waktu paling lambat $(L S)=L F-D[4]$

ES (early start) = waktu mulai paling awal kegiatan

LF (latest finish) = waktu paling akhir kegiatan selesai

$\mathrm{D}$

= waktu yang diperlukan untuk mengerjakan pekerjaan tersebut

Sedangkan untuk mengetahui jalur kritis dari suatu proyek maka dibutuhkan perhitungan slack. Slack merupakan waktu kelonggaran atau waktu diperbolehkannya suatu pekerjaan mengalami keterlambatan, jika slack berjumlah 0 maka pekerjaan tersebut berada di dalam jalur kritis yang artinya tidak boleh mengalami keterlambatan[4], selain itu pada jalur tersebut merupakan jalur yang memerlukan waktu penyelesaian paling lama. Perhitungan slack sebagaimana pada rumus (4):

$$
\text { slack }=L F-E F=L S-E S[4]
$$

Hasil dari perhitungan dan pengolahan data pekerjaan C03-check dengan CPM (Critical Path Method) terdapat pada tabel 4.

Tabel 4. Tabel Crictical Path Method C03-check Package

(Sumber: Data Diolah)

\begin{tabular}{|c|c|c|c|c|c|c|c|c|c|}
\hline NO & $\begin{array}{l}\text { TASK } \\
\text { CODE }\end{array}$ & DESC & PRE & $\mathbf{D}$ & ES & $\mathbf{E F}$ & $\mathbf{L S}$ & $\mathbf{L F}$ & SLACK \\
\hline 1 & A & MAINTENANCE PREPARATION & - & 4,8 & 0 & 4,8 & 5,52 & 10,3 & 5,52 \\
\hline 2 & B & OPEN ACCESS DOOR PANEL & A & 2 & 4,8 & 6,8 & 10,32 & 12,3 & 5,52 \\
\hline 3 & B1 & OPC/FUC ACCESS DOOR PANEL & $\mathrm{B}$ & 11,18 & 6,8 & 17,98 & 12,32 & 23,5 & 5,52 \\
\hline 4 & B2 & CLEANING ACCESS DOOR PANEL & B1 & 1,2 & 17,98 & 19,18 & 23,5 & 24,7 & 5,52 \\
\hline 5 & B3 & DVI ACCESS DOOR PANEL & $\mathrm{B} 2$ & 3,9 & 19,18 & 23,08 & 24,7 & 28,6 & 5,52 \\
\hline 6 & B4 & REM/INS ACCESS DOOR PANEL & B3 & 6,9 & 23,08 & 29,98 & 28,6 & 35,5 & 5,52 \\
\hline 7 & B5 & LUB ACCESS DOOR PANEL & B4 & 1,6 & 29,98 & 31,58 & 35,5 & 37,1 & 5,52 \\
\hline 8 & B6 & CLOSE ACCESS DOOR PANEL & B5 & 1,4 & 31,58 & 32,78 & 37,1 & 38,5 & 5,52 \\
\hline NO & $\begin{array}{l}\text { TASK } \\
\text { CODE }\end{array}$ & DESC & PRE & D & ES & $\mathbf{E F}$ & LS & $\mathbf{L F}$ & SLACK \\
\hline 1 & $\mathrm{~A}$ & MAINTENANCE PREPARATION & - & 4,8 & 0 & 4,8 & 8,1 & 12,9 & 8,1 \\
\hline 9 & $\mathrm{C}$ & OPEN ENGINE ACCESS PANEL & $\mathrm{A}$ & 3,6 & 4,8 & 8,4 & 12,9 & 16,5 & 8,1 \\
\hline 10 & $\mathrm{C} 1$ & OPC/FUC ENGINE ACCESS PANEL & $\mathrm{C}$ & 2,2 & 7 & 10,6 & 16,5 & 18,7 & 8,1 \\
\hline 11 & $\mathrm{C} 2$ & GVI ENGINE ACCESS PANEL & $\mathrm{C} 1$ & 4,5 & 11,5 & 15,1 & 18,7 & 23,2 & 8,1 \\
\hline 12 & $\mathrm{C} 3$ & DVI ENGINE ACCESS PANEL & $\mathrm{C} 2$ & 3,4 & 14,9 & 18,5 & 23,2 & 26,6 & 8,1 \\
\hline 13 & $\mathrm{C} 4$ & SDI ENGINE ACCESS PANEL & $\mathrm{C} 3$ & 6,2 & 21,1 & 24,7 & 26,6 & 32,8 & 8,1 \\
\hline 14 & $\mathrm{C} 5$ & REM/INS ENGINE ACCESS PANEL & $\mathrm{C} 4$ & 2,1 & 23,2 & 26,8 & 32,8 & 34,9 & 8,1 \\
\hline 15 & C6 & CLOSE ENGINE ACCESS PANEL & $\mathrm{C} 5$ & 3,6 & 26,8 & 30,4 & 34,9 & 38,5 & 8,1 \\
\hline
\end{tabular}




\begin{tabular}{|c|c|c|c|c|c|c|c|c|c|}
\hline NO & $\begin{array}{l}\text { TASK } \\
\text { CODE }\end{array}$ & DESC & PRE & $\mathbf{D}$ & ES & EF & $\mathbf{L S}$ & $\mathbf{L F}$ & SLACK \\
\hline 1 & A & MAINTENANCE PREPARATION & - & 4,8 & 0 & 4,8 & 0 & 4,8 & 0 \\
\hline 16 & D & $\begin{array}{l}\text { OPEN EMPENAGE ACCESS } \\
\text { PANEL }\end{array}$ & A & 4,1 & 4,8 & 8,9 & 4,8 & 8,9 & 0 \\
\hline 17 & D1 & $\begin{array}{l}\text { OPC/FUC EMPENAGE ACCESS } \\
\text { PANEL }\end{array}$ & $\mathrm{D}$ & 3,2 & 8,9 & 12,1 & 8,9 & 12,1 & 0 \\
\hline 18 & $\mathrm{D} 2$ & GVI EMPENAGE ACCESS PANEL & D1 & 1 & 12,1 & 13,1 & 12,1 & 13,1 & 0 \\
\hline 19 & D3 & DVI EMPENAGE ACCESS PANEL & $\mathrm{D} 2$ & 4,1 & 13,1 & 17,2 & 13,1 & 17,2 & 0 \\
\hline 20 & D4 & SDI EMPENAGE ACCESS PANEL & D3 & 6 & 17,2 & 23,2 & 17,2 & 23,2 & 0 \\
\hline 21 & D5 & $\begin{array}{l}\text { REM/INS EMPENAGE ACCESS } \\
\text { PANEL }\end{array}$ & D4 & 9,3 & 23,2 & 32,5 & 23,2 & 32,5 & 0 \\
\hline 22 & D6 & $\begin{array}{l}\text { LUB EMPENAGE ACCESS } \\
\text { PANEL }\end{array}$ & D5 & 1,9 & 32,5 & 34,4 & 32,5 & 34,4 & 0 \\
\hline 23 & D7 & $\begin{array}{l}\text { CLOSE EMPENAGE ACCESS } \\
\text { PANEL }\end{array}$ & D6 & 4,1 & 34,4 & 38,5 & 34,4 & 38,5 & 0 \\
\hline NO & $\begin{array}{l}\text { TASK } \\
\text { CODE }\end{array}$ & DESC & PRE & D & ES & $\mathbf{E F}$ & LS & LF & SLACK \\
\hline 1 & A & MAINTENANCE PREPARATION & - & 4,8 & 0 & 4,8 & 8,78 & 13,6 & 8,78 \\
\hline 24 & E & $\begin{array}{l}\text { OPEN FUSELAGE ACCESS } \\
\text { PANEL }\end{array}$ & A & 5,5 & 4,8 & 10,3 & 13,58 & 19,1 & 8,78 \\
\hline 25 & E1 & $\begin{array}{l}\text { OPC/FUC FUSELAGE ACCESS } \\
\text { PANNEL }\end{array}$ & $\mathrm{E}$ & 1,32 & 10,3 & 11,62 & 19,08 & 20,4 & 8,78 \\
\hline 26 & $\mathrm{E} 2$ & GVI FUSELAGE ACCESS PANEL & E1 & 1,2 & 11,62 & 12,82 & 20,4 & 21,6 & 8,78 \\
\hline 27 & E3 & DVI FUSELAGE ACCESS PANEL & E2 & 5,5 & 12,82 & 18,32 & 21,6 & 27,1 & 8,78 \\
\hline 28 & $\mathrm{E} 4$ & $\begin{array}{l}\text { REM/INS FUSELAGE ACCESS } \\
\text { PANEL }\end{array}$ & E3 & 5 & 18,32 & 23,32 & 27,1 & 32,1 & 8,78 \\
\hline 29 & E5 & LUB FUSELAGE ACCESS PANEL & E4 & 0,9 & 23,32 & 24,22 & 32,1 & 33 & 8,78 \\
\hline 30 & E6 & $\begin{array}{l}\text { CLOSE FUSELAGE ACCESS } \\
\text { PANEL }\end{array}$ & E5 & 5,5 & 24,22 & 29,72 & 33 & 38,5 & 8,78 \\
\hline NO & $\begin{array}{l}\text { TASK } \\
\text { CODE } \\
\end{array}$ & DESC & PRE & D & ES & $\mathbf{E F}$ & $\mathbf{L S}$ & $\mathbf{L F}$ & SLACK \\
\hline 1 & $\mathrm{~A}$ & MAINTENANCE PREPARATION & - & 4,8 & 0 & 4,8 & 6,45 & 11,3 & 6,45 \\
\hline 31 & $\mathrm{~F}$ & OPEN WING ACCESS PANEL & $\mathrm{A}$ & 4,1 & 4,8 & 8,9 & 11,25 & 15,4 & 6,45 \\
\hline 32 & F1 & OPC/FUC WING ACCESS PANEL & $\mathrm{F}$ & 7 & 8,9 & 15,9 & 15,35 & 22,4 & 6,45 \\
\hline 33 & $\mathrm{~F} 2$ & GVI WING ACCESS PANEL & $\mathrm{F} 1$ & 2,6 & 15,9 & 18,5 & 22,35 & 25 & 6,45 \\
\hline 34 & $\mathrm{~F} 3$ & DVI WING ACCESS PANEL & $\mathrm{F} 2$ & 3,15 & 18,5 & 21,65 & 24,95 & 28,1 & 6,45 \\
\hline 35 & F4 & REM/INS WING ACCESS PANEL & F3 & 2,5 & 21,65 & 24,15 & 28,1 & 30,6 & 6,45 \\
\hline 36 & F5 & LUB WING ACCESS PANEL & $\mathrm{F} 4$ & 3,8 & 24,15 & 27,95 & 30,6 & 34,4 & 6,45 \\
\hline 37 & F6 & CLOSE WING ACCESS PANEL & F5 & 4,1 & 27,95 & 32,05 & 34,4 & 38,5 & 6,45 \\
\hline NO & $\begin{array}{l}\text { TASK } \\
\text { CODE }\end{array}$ & DESC & PRE & D & ES & EF & LS & LF & SLACK \\
\hline 38 & $\mathrm{G}$ & POST MAINTENANCE & 2,8 & $\begin{array}{l}\text { B6, } \\
\text { C6, } \\
\text { D6, } \\
\text { E4, } \\
\text { F5 }\end{array}$ & 38,5 & 41,3 & 38,5 & 41,3 & 0 \\
\hline
\end{tabular}


Diagram dari CPM (Critical Path Method) dapat dilihat pada Gambar 1, beserta dengan urutan pekerjaan yang dilakukan.

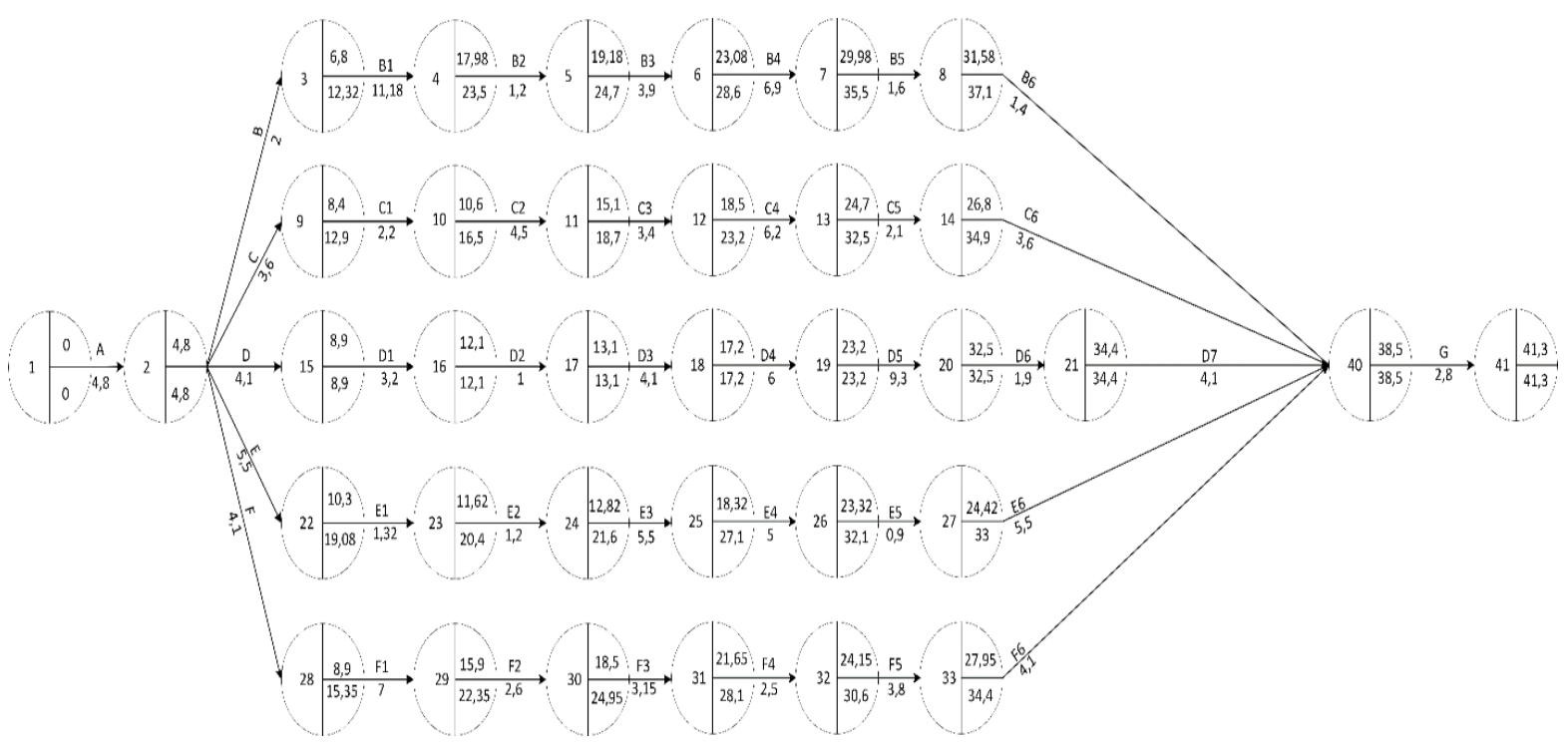

Gambar 1. Diagram Crictical Path Method C03-check (Sumber: Data Diolah)

Merujuk pada Tabel 4 dan Gambar 1, hasil perhitungan slack menunjukan bahwa pada jalur D diperoleh nilai slack $=0$ yang artinya pada jalur D tidak memiliki waktu kelonggaran untuk penundaan pekerjaan, sehingga dapat dikatakan bahwasannya pada jalur D yaitu A-D-D1-D2-D3-D4-D5-D6-D7-G merupakan jalur kritis dalam paket perawatan C03-check yang tidak boleh mengalami keterlambatan. Jika pada jalur D mengalami keterlambatan maka akan mempengaruhi total TAT (turn around time) dari paket perawatan C03-check. Hasil ini memiliki korelasi dengan hasil perhitungan maju, yang mana diperoleh TAT untuk jalur D adalah 38,5 manhours yang merupakan TAT paling lama jika dibandingkan jalur - jalur yang lain.

Dari hasil perhitungan slack juga diperoleh bahwa jalur E memiliki slack paling banyak yaitu 8,78 manhours, dan memerlukan waktu paling sedikit dalam penyelesaiannya yaitu 29,72 manhours. Hal ini dapat menjadi bahan pertimbangan dan strategi dalam pelaksanaan kegiatan paket perawatan C03-check dilapangan. Karena jalur E memiliki banyak kelonggaran tenggang waktu maka alokasi manpower dan pelaksanaan bisa terlebih dahulu dialokasikan untuk jalur D yang merupakan jalur kritis. Hal yang sama juga bisa diterapkan pada jalur - jalur yang lain yang masih memiliki tenggang kelonggaran waktu akan tetapi tidak boleh melebihi batas LS (latest start) dari hasil perhitungan mundur. Sedangkan apabila semua pekerjaan pada setiap jalur dimulai pada waktu yang sama yaitu ketika proyek dimulai, maka setiap jalur pekerjaan yang telah selesai terlebih dahulu, dapat kemudian dialokasikan untuk jalur pekerjaan lain yang masih belum selesai.

Dari hasil perhitungan setiap jalur, telah diperoleh hasil waktu penyelesaian paling lama adalah pada jalur D yaitu 38,5 manhours yang apabila ditambah dengan kegiatan post maintenance akan menjadi 41,3 manhours. Maka dari hasil perhitungan ini diperoleh total TAT (turn around time) untuk paket C03-check adalah : 


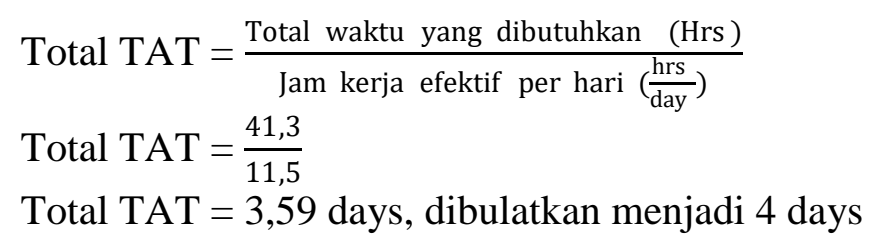

Maka dari hasil pengolahan seluruh data paket perawatan C03-check diperoleh TAT (turn around time) yang direncanakan untuk menyelesaikan paket perawatan C03check adalah 4 hari kerja.

\section{Kesimpulan}

Hasil perencanaan dengan metode CPM (critical path method) untuk paket perawatan C03-check pada pesawat Airbus A320-200, maka disimpulkan bahwa untuk menyelesaikan paket perawatan C03-check memerlukan waktu 4 hari kerja, dengan jalur kritis berada pada jalur D yaitu pada empenage access panel dengan urutan pekerjaan A-D-D1-D2-D3-D4-D5-D6-D7G.

\section{Ucapan Terimakasih}

Ucapan terimakasih penulis sampaikan kepada P3M STT Adisutjipto yang telah berperan dalam memberikan bantuan dana dalam pelaksanaan penelitian ini.

\section{Daftar Pustaka}

[1] Airbus, 2018, Maintenance Planning Document A320-200, Airbus S.A.S., Prancis.

[2] Kinnison H.A., Siddiqui T., Aviation Maintenance Management, McGrawHill, New York

[3] Kasiram, Moh, 2008, Metodologi Penelitian, Malang, UIN-Malang Pers.

[4] Soeharto, I., 1999, Manajemen Proyek, Erlangga, Jakarta.

[5] Wibowo, A., \& Utomo, J. (2010). Eksplorasi Metode Bar Chart, Cpm, Pdm, Pert, Line Of Balance Dan Time Chainage Diagram Dalam Penjadwalan Proyek Konstruksi (Doctoral dissertation, magister teknik sipil).

[6] Sudaryanto, D. H., \& Kom, S. (2013). Perhitungan Kebutuhan Pegawai Berbasis Beban Kerja. In PPSDM MIGAS Cери Forum Manajemen (Vol. 3, No. 3).

[7] Agustiar, I., \& Handrianto, R. (2018). Evaluasi Penjadwalan Proyek Menggunakan Metode Cpm Dan Kurva S. Wahana Teknik, 7(2).

[8] Dimyati, D. H., \& Nurjaman, K., 2014. Manajemen Proyek, Pustaka Setia, Yogyakarta. 
Fajar Khanif Rahmawati, Suyudi Imam Prakoso

PPT-16 